Ww record with regret the death of one of the oldest and most distinguished officers of the medical profession in the Royal Navy, Robert M'Cormick, F.R.C.S., R.N., Deputy Inspector-General of Hospitals and Fleets, in the ninetyfirst year of his age. He was a pupil of Sir Astley Cooper at Guy's Hospital. He was a distinguished geologist and zoologist, accompanied various arctic and antarctic expeditions, and was an able and interesting author.

Mr. Lawson TaIt has been elected Honorary President and an Honorary Fellow of the Glasgow Obstetrical and Gynæcological Society, and an Honorary Fellow of the Edinburgh Obstetrical Society.

\section{THE CARE OF THE TEETH IN CHILDHOOD. 1}

By Francis Fox, M.R.C.S., L.R.C.P. Ed., DENTAL SURGEON TO THE VICTORIA HOSPITAL FOR CHILDREN, ETC.

THE care of the teeth in childhood is subject matter of real and great importance, and should claim the attentive consideration of medical men, and especially of those whose energies are exerted on behalf of the young. Much may be done during the early years of life, especially in that important epoch-the second dentition,-by combating deleterious influences, to further the development of sound structures, and to give some promise of useful masticating agents. Doubtless many of the dental troubles of adult life are due to a careless disregard of the teeth when first erupted, and during the earlier years of life, at a time when frequent inspection and judicious attention may encourage the hope of some immunity from dental disease. [In order the more fully to emphasise this statement Mr. Fox reviewed certain physiological facts respecting the development of the dental tissues and maxillary structures, dwelling particularly on the periods of calcification, and pointing ont the liability to disarrangement of this process by any untoward circumstance affecting the general nutrition and growth of the body, resulting in imperfect deposition of calcific matter, thus rendering the tissues less cohesive, and necessarily less able to withstand the causes of decay. The systemic disturbances which are so apt to occur both in connexion with the first and second dentition, arising from dental irritation, were then mentioned; and the author passed to the consideration of some of the affections to which the teeth of children are liable.] Caries is the most frequent disease of the dental structures, occurring as a rule in early adolescence, soon after the teeth have been subjected to the exposure and wear and tear of their function, when the perfection of their structural development is put to the test and is but too often found wanting, and in consequence of inherent defect incapable of resisting the action of pernicious influences, such as pressure of contiguous teeth, the solvent properties of abnormal saliva, and acid mucous secretion of the gums and oral tissues. These conditions being the immediate causes of decay, the deposition of tartar of a peculiarly destructive character forming a nidus for the growth of bacteria and leptothrix, and rapidly affecting the enamel by disintegrating its structure; alveolar abscess and necrosis of the roots of temporary teeth; the presence in the dental arch of supernumerary teeth, and other abnormal conditions call for prompt treatment. [Irregularity in the position of the permanent teeth was then fully considered, and the importance of early treatment of this condition insisted upon.] For not only is an irregular position of the teeth disfiguring, but, by the increased and continuous pressure upon contiguous teeth which this condition usually entails, it constitutes a most frequent cause of decay of their structures, as well as being an occasional cause of certain systemic derangements arising from reflex nervous irritation. Wimpole-street, $\mathrm{W}$.

I A brief Abstract of the Address read before the Medical Officers of Schools' Association.

\section{OPENING OF THE PROVINCIAL MEDICAL SCHOOLS.}

\section{Liverpool Medical School.}

Mr. BANKs commenced by remarking upon the extraordinary diversities of opinion held upon the question of medical education, and believed that this arose largely from the fact that those who spoke about it were too often only acquainted with one aspect of the case. For a man to speak with authority he must be a teacher of long standing. Nay, more, he must be still engaged in active teaching, so. as to be completely conversant with the capacity of the medical student, with the time which is at his disposal and with the work which can be put into that time. Furthermore, he must be a man in practice, and that practice of such a nature as will bring him into contact with medical men of all kinds, so that he may know what sort of men students ultimately are transformed into, and also the things in which they are deficient. At the present moment we have on one side the professor (very of ten not a medical man at all) clamouring for more preliminary science, and announcing that, unless he can teach his subject thoroughly and fully, he would rather not teach at all. On the other side we have the practitioner complaining that students are turned out lamentably ignorant of practical work and unacquainted with com. mon diseases, so that as assistants they are useless. This gentleman wants to revive the good old apprenticeship days, and bring back the art of physicking to its old position of supremacy. Last summer the General Medical Council considered the whole question most carefully. They admitted the truth of the charge that modern students did not know as much practical work as they ought to do when they received their degrees or diplomas, but they saw no possible way to the introduction of an apprenticeship scheme into a four years' curriculum. They therefore unanimously expressed their opinion that the curriculum of the future should be a five years' one, and announced their intention of seeing this carried out. As to the question of whether a scientitic education or a so-called practical one was the best for the student, he had not a doubt of the immense superiority of the scientific one; and he drew a sketch of the young doctor who entered life with a thorough scientific training, and found himself for a while utterly at sea in practice, and of the other who had had the practical training only, and who was an accomplished practitioner (of a kind) before even he had got his qualification. He showed how the former speedily made up his deficiencies and advanced in his profession, while the other remained just where he began. But the question was as to the kind of science which medical students should be taught, and he made a vigorous attack upon the teaching of botany, zoology, higher chemistry, and advanced physics, demanded nowadays for most degrees. $\mathrm{He}$ complained that an infinity of time was wasted by the student in these studies, which he proceeded to obliterate from his memory as rapidly as possible so soon. as he had passed his examinations. What was learnt from them was absolutely useless to a modern doctor, while the contention that they constituted a great mental training was met by the answer that there were sciences, actually bearing upon practice, which were equally efficacious as a means of mental training. In anatomy, physiology, and pathology we had everything that botany and zoology could supply as a means of teaching exact observation. $\mathrm{He}$ strongly complained of the shameful neglect of the teaching of true scientific pathology in this country, and held that the time now wasted upon the preliminary sciences if spent upon pathology would be a life-long benefit to the student who had no means of pursuing it from the moment he left his school. Turning to the question of defective practical training, he called attention to the recommendations of the General Medical Council, which urged that all lectures (in addition to being curtailed in number) should also be terminated by the end of the fourth year, leaving the fifth year for practical work alone. Great latitude was left to the student as to how he should spend this last year. He might continue to attend the clinical teaching of a hospital, he might go to a dispensary, or he might become pupil to a 